\title{
Organizational options for preventing work-related stress in knowledge work
}

Ipsen, Christine; Jensen, Per Langaa

Published in:

International Journal of Industrial Ergonomics

Link to article, DOI:

10.1016/j.ergon.2012.02.006

Publication date:

2012

Document Version

Peer reviewed version

Link back to DTU Orbit

Citation (APA):

Ipsen, C., \& Jensen, P. L. (2012). Organizational options for preventing work-related stress in knowledge work. International Journal of Industrial Ergonomics, 42(4), 325-334. https://doi.org/10.1016/j.ergon.2012.02.006

\section{General rights}

Copyright and moral rights for the publications made accessible in the public portal are retained by the authors and/or other copyright owners and it is a condition of accessing publications that users recognise and abide by the legal requirements associated with these rights.

- Users may download and print one copy of any publication from the public portal for the purpose of private study or research.

- You may not further distribute the material or use it for any profit-making activity or commercial gain

- You may freely distribute the URL identifying the publication in the public portal

If you believe that this document breaches copyright please contact us providing details, and we will remove access to the work immediately and investigate your claim. 
ORGANIZATIONAL OPTIONS FOR PREVENTING WORK-RELATED

\section{STRESS IN KNOWLEDGE WORK}

Christine Ipsen, Ph.D., Associate Professor (Corresponding author)

Department of Management Engineering

Building 424

The Technical University of Denmark

DK- 2800 Kgs. Lyngby, Denmark

chip@dtu.dk

Phone: $+45-45256014$

Fax: $+45-45933435$

\section{Per Langaa Jensen, Ph.D. Professor}

Department of Management Engineering

Building 424

The Technical University of Denmark

DK- 2800 Kgs. Lyngby, Denmark

plaj@dtu.dk 


\section{ABSTRACT}

Recent studies point to work-related stress as an increasing problem for knowledge workers. However, the working life in knowledge-intensive companies is often described as good and stimulating. The aim of this study is to explore the organizational options for preventing workrelated problems in knowledge work. This calls for a study of the characteristics of knowledge work, stress management interventions and an in-depth analysis of the organizational factors causing frustrations and work-related problems in relation to knowledge work. In a qualitative study, 27 respondents were interviewed. They represented different stakeholders in five Danish knowledge-intensive companies, which comprised two consultancies and three engineering consulting companies.

The study shows that knowledge work comprises a paradox, since the same work-related or organizational issues could be experienced as both an opportunity and a source of stress. The stress interventions applied are short-term and focus on the individual; consequently, they affect longterm prevention, which focuses on changing the organizational and managerial circumstances. Finally, the in-depth analysis shows that the organizational factors in the organizational design are not aligned, which consequently has an unsolicited effect on both daily activities and the human factors.

The findings suggest that if the central components in the organizational design were aligned, the benefits could include reduced absenteeism and turnover as well as higher productivity.

\section{Relevance to industry}

The paper identifies organizational options on which managers, employees and ergonomists can focus when initiating new stress management practices and preventive changes aimed at redesigning knowledge work.

Keywords: See file. 


\section{INTRODUCTION}

Studies focusing on strain, workload, work-related stress etc. are typically concerned with industrial or traditional service companies, especially those involved in mass service, and rarely knowledgeintensive companies (European Foundation for the Improvement of Living and Working Conditions, 2007). Work as an academic, which includes knowledge work, is perceived to offer a good and developing job with working conditions characterized by a high level of influence, control, flexibility and autonomy (M. Kompier \& Cooper, 1999; Parker \& Wall, 1999).

Earlier studies, which are typically based on the work of R. Karasek and T. Theorell and their Job Decision Latitude model (Karasek, 1979; Karasek, 1990)), find that such working conditions reflect a good psychosocial environment.

Recent studies point out that work-related stress is an increasing problem for knowledge workers, despite employee control and influence, and that knowledge work has characteristics that can cause frustration, work-related stress and reduced performance (Griffiths, 1999; Ipsen, 2007; McClenahan, Giles, \& Mallet, 2007; Stavroula, Griffiths, \& Cox, 2003; WHO, 1999).

The share of knowledge workers experiencing work-related stress has been questioned. A Danish survey performed by the National Institute of Public Health shows that the number of people occasionally experiencing stress increases with their educational level (Statens Institut for Folkesundhed, 2003). Most preventive activities focus on the ability of the individual to cope with stress (M. Kompier \& Cooper, 1999; Murphy, 1988; Murphy \& Sauter, 2003; Newton, Handy, \& Fineman, 1995), which is also reflected in the growing number of articles, self-assistance books and courses on worksite stress management. 
Against this background, a study has been conducted with the overall objective to identify what organizational options exist for preventing work-related problems in knowledge work, and which also considers the implications for central actors.

The study was carried out in cooperation with five knowledge-intensive companies, based on a qualitative research methodology. To qualify the overall objective, three other research questions were addressed on the basis of the empirical material produced:

1. What characterizes the working life of knowledge workers?

2. What characterizes the stress management interventions in knowledge-intensive companies?

3. What organizational factors can be identified that cause frustrations and work-related problems in relation to knowledge work?

This article is therefore structured as follows: First, the theoretical framework of the research is introduced; second, the research methodology is presented; and then the results, discussion and the limitations of the study. Finally, the conclusions are presented, and the implications of the results are discussed.

\section{KNOWLEDGE WORK}

The project's research approach has been trans-disciplinary; therefore, several supporting theories have been used. The link between knowledge-intensive work and stress management is vague. It is thus characteristic of the knowledge management literature that it is prescriptive, suggesting strategies for improvement of the work and human performance without considering the human factors. Conversely, the stress management literature scarcely embraces knowledge work and the production factors related to it. 
Since it is difficult to identify one general knowledge management theory to support this study, the theories used in this article are thus to be seen as the premise for the claim put forward. The organizational behavior theories presented in this article, such as systems thinking and organizational learning, are thus chosen because they are generally accepted and applicable within the knowledge management domain.

Regarding the understandings of human factors related to knowledge-intensive work and how problematic issues can be dealt with, this research thus draws on theories from other studies and traditions such as prevention of work-related stress and psychosocial studies.

\subsection{Knowledge-intensive work}

There are several theoretical and empirical conceptions of the knowledge-intensive company (Heisig, 2009). One widespread conception is that in this type of company, knowledge transfer and knowledge sharing are crucial for survival and progress. Thus, knowledge has become the competitive parameter (T. H. Davenport \& Prusak, 1998; Drucker, 1988; Krogh \& Roos, 1996). This definition covers many different branches and trades. In this study, the term knowledgeintensive company applies to a company characterized by non-material input and output, with the individuals as the primary bearers of knowledge ("pure" knowledge companies (Alvesson, 1995). Examples are consulting companies, law firms and universities, in contrast to companies where knowledge is also embedded in a technology (high-tech companies), such as biotech and IT companies. In the work process, knowledge is acquired, processed, created, preserved and shared, and finally sold. The knowledge product that is developed and produced in projects is based on customer needs combined with professional and personal knowledge (Alvesson, 1995; Alvesson, 2004; Nonaka \& Teece, 2002; Starbuck, 1992). 
Consequently, the employees become the competitive parameter in knowledge-intensive companies. This implies that in order to perform well the companies need educated and highly skilled employees with significant competences and experience. Specifically, general management and engineering consulting companies are studied, since they all fall within this framework.

The task that they perform is often social (T. H. Davenport, 2005). Problems are addressed; knowledge is exchanged in order to develop new knowledge; and solutions are analyzed. And the assignment or task is often carried out in teams, where each member is responsible for a part. This requires the ability to collect, create, process, share, maintain and communicate knowledge. These abilities together form the core processes of knowledge-intensive work (T. H. Davenport \& Prusak, 1998) (Krogh \& Roos, 1996; Nonaka \& Takeuchi, 1995).

The literature on the management of knowledge and knowledge work mainly focuses on optimizing knowledge production and what is necessary in order to accomplish this (Newell et al., 2001). Other effects in terms of human factors, behavior, working life etc. play a secondary role., Within this type of literature, however, several issues have the potential to affect working life and thus represent potential sources of stress. Such critical issues could be: conflicting conceptions of knowledge between managers and employees; the impact of performance measurement; the fundamental dependency of knowledge in knowledge work and the boundaries of organizational structures.

\section{DIFFERENT LEVELS OF STRESS INTERVENTION}

Interventions to alleviate work-related problems and stress can have numerous forms. Murphy (1988) has identified three approaches to stress management, labeled primary, secondary and tertiary interventions. These approaches focus either on the organization $\left(1^{\circ}\right)$, the interrelation 
between the individual and the organization $\left(2^{\circ}\right)$, or the individual $\left(3^{\circ}\right)($ DeFrank \& Cooper, 1987;

Murphy, 1988; Newton et al., 1995) (See Table 1).

[Insert Table 1]

In practice, most activities address the individual in order to improve the employee's ability to cope with stress (Kompier \& Cooper, 1999; Murphy, 1988; Murphy \& Sauter, 2003). The quantity of articles, self-assistance books and courses on workplace stress management indicate that this has been a distinct trend in recent years.

In order to address primary stress-preventive actions in knowledge work through organizational development, it is important to understand the relation between the sources of work-related problems and the organizational design of the workplace (Dettinger \& Smith, 2006; Ipsen, 2007; Smith \& Sainfort, 1989; Sørensen \& Holman, 2010).

This kind of work comprises problematic circumstances, however, which are found to constitute potential sources of work-related stress. The work of knowledge workers or highly educated employees has been considered to be good and low-risk work. Nevertheless, newer empirical studies and surveys indicate the opposite (Buch \& Andersen, 2008; Ipsen, 2006; McClenahan et al., 2007), thus revealing a clash between the early research findings and understandings of the relation between knowledge work and stress and the theoretical study of knowledge work. The latter findings are supported by the recent studies of psychosocial conditions among knowledge workers.

To conclude, the literature study shows that knowledge work focuses on the performanceoriented optimization of the processes and not on the joint optimization of performance and working conditions - and consequently, not on the psychosocial aspects and work-related stress. 
Since this relation has not been analyzed from a human factor perspective in this context, it is the aim of this study to explore the organizational options for preventing work-related stress in knowledge work.

\section{CASE STUDY METHODOLOGY}

A qualitative research approach was chosen as the framework for the study. The point of departure was hermeneutic and pragmatic, with the aim to analyze, explore and thus gain insight into the characteristics of knowledge work and the relation between knowledge work and the psychosocial environment. The basic premise in this study is therefore examining and understanding a phenomenon and not detecting and documenting the prevalence of the phenomenon (i.e. the psychosocial working environment in knowledge-intensive companies) and the possibilities to prevent work-related problems and strains in the job. A multiple case study was conducted in five knowledge-intensive companies, based primarily on interviews (see Table 2). Together with the multiple case studies, a participatory inquiry approach was chosen. They were used sequentially, with the aim to increase the quality of the data and add insight (Johnson \& Onwuegbuzie, 2004; Johnson, Onwuegbuzie, \& Turner, 2007).

In terms of organizational development, the premise is that collective reflections and actions are an integrated part in this process in order to secure sustainability of the new activities, since, as a responsible unit and as generators of ideas in a development process, the collective can generate more than the individual (M. Kompier, Geurts, Gründemann, Vink, \& Smulders, 1998; Mikkelsen, 1995).

The approach and the methods were all chosen to provide the relevant data for gaining insight into the basic characteristics of knowledge work, the related risks and preventive strategies. 
[Insert Table 2]

The respondents were therefore chosen on the basis of their experiences and insight into knowledge work and the ways in which critical situations are handled. All company levels are represented.

The companies were chosen from among larger consulting companies with headquarters either in Denmark, the UK or USA. Contact was established solely with the Danish offices. The smaller size of the population (27 respondents) offers the opportunity to focus on the 'richness' of data from each respondent, thus opening for an in-depth analysis. On the other hand, the representativity may be questioned; therefore, the scope of this study has been to formulate a hypothesis for future studies within prevention of work-related stress in knowledge work, and in order to open a dialogue with managers, employees and other central actors in knowledge-intensive companies on preventive actions in accordance with general principles of hermeneutics.

\subsection{Conducting the interviews}

The interviews were conducted before the financial crisis came into effect. An interview-based case study approach was used. The interviews were semi-structured and open-ended, and evolved from a number of general questions rather than from specific ones. All conducted interviews focused on knowledge work; how it is organized; derived problems and the causes behind these problems; as well as the dominating stress management interventions initiated to handle the problems. However, different priorities were given to the subjects, depending on the tasks and position of the respondent, in order to gain a deeper understanding of the characteristics of knowledge work and the relation between knowledge work and the psychosocial environment, as well as the respondents' perception, role and actions in stress management interventions. The interview guide did not vary 
within the five groups of actors: HR-managers, knowledge-managers, first-line managers, employees, and people working with human factors.

The interviews conducted with the employees and their first-line managers focused on all subjects listed, whereas the interviews with the HR-managers focused on work-related problems in knowledge work, the perceived causes behind these problems, and the dominating stress management interventions initiated in the particular company. The interviews with the knowledgemanagers focused primarily on the organization of knowledge work, derived problems and the causes behind these problems.

The interviews were all conducted face-to-face and took place in meeting rooms or the respondents' own offices, with only the interviewer and the respondent present. Typically, the interview lasted for about an hour.

All interviews were recorded and transcribed afterwards. In addition, documents presented by the respondents were analyzed. These included organizational strategies and diagrams, knowledge management strategies and HR-reports regarding policies etc. Together with general workplace observations, all this input provided important background information that contributed to developing an understanding of the respondent's perspective and understanding. This was used during the coding of the interviews and subsequently throughout the analysis (Bryman, 2004; Collis \& Hussey, 2003; Kvale, 1994; Maalфe, 2002).

\subsection{Model of analysis - organizational interrelations and causes}

The purpose of the data analysis was twofold: first, to identify and outline the characteristics of knowledge work and how problematic issues and work-related stress were being managed. Since the study had an analytical and explorative aim, the search through a cross-case analysis was for patterns of relations between personal work experiences and the characteristics of knowledge work. 
This analysis provides answers to research question one and two. The second purpose was to identify the organizational factors causing frustrations and work-related problems in knowledge work through an in-depth analysis in order to answer the third research question. Together, the results provide answers to the overall objective of the study.

Using the program, "ATLAS ti.5", the data were structured according to a list of categories generated from the core themes in two of the research questions, 1 together with the components of the two conceptual models: the "Six Golden Grains" (Kristensen, 1999), and Galbraith's "Star Model" (Galbraith, 2002). The former model comprises six organizational and interpersonal conditions that must be present in a work place in order to have good and healthy job design and a good working life (Kristensen, 2004; Kristensen, Hannerz, Hфegh, \& Borg, 2005)

The latter model is an organizational design model that is explained below.

The chosen approach, also termed "categorization of meaning", aims at coding an interview and the respondent's first-order statements (Dahler-Larsen, 2002) into categories that are defined in advance or become apparent in the course of the analysis (Kvale, 1994). Besides the nine known categories defined in advance, six new categories became apparent during the analysis. The predefined and new categories are listed in Table 3.

\section{[Insert Table 3]}

After the first coding, all the statements regarding one particular code were gathered in one document. All 15 documents were then systematically analyzed using graphic displays. The data were thus clustered and interrelated with arrows so that a statement expressed a link between a

\footnotetext{
${ }^{1}$ What characterizes knowledge work and working-life in knowledge-intensive companies How is work-related stress or problematic issues managed?
} 
personal experience of the work and the characteristics of the work. It thus became possible to identify subcategories and potential relations among the respondents' first-order statements (DahlerLarsen, 2002). The analysis resulted in three themes embracing the listed categories. The three themes were all closely related to the overall objective of the project and the research questions.

1. Human factors in knowledge work

2. Stress management interventions in knowledge work

3. Organizational causes of the work-related problems

The theme "Human factors in knowledge work" relates to the first research question, and the corresponding analysis embraces the categories listed in Table 4. The second research question is answered on the basis of the analysis, including the categories represented in the second theme. Finally, the in-depth analysis of the "Organizational causes to the work-related problems" involves the categories listed below and relates to the final research question.

\section{[Insert Table 4]}

The results of the first part of the analysis, which corresponds to themes 1 and 2, are presented in sections 5.1 and 5.2.

In alignment with Smith and Sainfort (1989), it is a basic assumption that the organizational design determines the factors influencing the work-related problems and working life. In order to identify the organizational factors causing frustrations and work-related problems in relation to knowledge work, an in-depth analysis was then conducted in order to answer the third research question. The results are presented in section 5.3. 
The analysis showed that if primary alignments are to be established, a joint optimization of production and working conditions must be established. This opens for identification of potential primary intervention strategies and the design of new stress management practices.

Combining the described models does not provide any instructions about how to solve the problems, but it does open for a dialogue on how knowledge work and daily practices are designed, and how this influences the working life of the knowledge worker.

The analytical work resulted in uncovering misalignments, from a human factor perspective, which could explain the respondents' problems and challenges. The outcome of the analysis was verified via a first order communicative validity process (a Member Check), in which several relevant, experienced actors within the field of practice were presented with the results and asked to comment on them. This research activity was carried out in order to clarify the credibility and authenticity of the observations and conclusions (Dahler-Larsen, 2002). The Member Check showed general agreement and recognition of the picture presented regarding the characteristics of knowledge work, and also provided our understanding with more nuances. The second order constructions were presented in different academic forums, such as workshops in academia and conferences, plus internal seminars with a reviewer, since it cannot be expected that respondents can relate to or approve a second order interpretation (Dahler-Larsen, 2002). The aim was to test the validity of the analysis in relation to the theoretical and methodological scope of the study.

The methodology and axiology presented above provides a judicious scope for the study. However, it could implicate that individual and successful actions are not identified and credited, due to the fact that the study's focus is on collective actions.

\section{RESULTS}


In this section, the results are presented based on the categorization of the respondents' first order statements and the data analysis which resulted in three themes, each answering one of the three research questions. All together, they form the basis for fulfilling the overall objective of the study.

\subsection{Human factors in knowledge work}

The results reported below draw on the first analysis and focus on the characterization of knowledge work and how it is being experienced. It thus provides a picture of 'the condition' of the human factors in knowledge work in the case companies.

\subsubsection{IT IS A SOVEREIGN JOB}

When questioned about their working life, the first spontaneous response from both employees and managers was that working with knowledge was challenging and interesting. It was also understood to provide an opportunity to work together with competent young people who provide an inspiring atmosphere and are good friends. Neither assignments nor workdays were alike; there were no routines, and everyone was free to work wherever (home, headquarters, or at customers' establishments), whenever, and using whatever method to solve a self-selected assignment. Working hours had no set time limit, although a minimum number of hours had to be invoiced to the customers.

As one consultant put it: "Knowledge work is a sovereign job; it provides you with a lot of possibilities. It can be very frustrating and some people tend to be stressed." The companies also provide various services for the employees, such as child daycare, good chefs in the canteen, organic food products, clubs, company cafés, family days etc. Therefore, it is possible to state that knowledge work comprises all the central aspects that support a sound and healthy psychosocial environment. 


\subsection{2 "KNOWLEDGE WORK - IT EATS YOU ALIVE..."}

Besides being a sovereign job, the work also presents several disadvantages. Evidently, the factors pointed out as supporting the feeling of having a sovereign job also have a downside.

One employee put it this way: "Freedom is an essential part of the job; however, knowledge work eats you alive if you don't know when and where to draw the line." And as another put it: "Stress is a condition which comes with the job." These two statements are representative of the way employees expressed their experience with knowledge work. Some stated it was stressful; others found it frustrating to always having to be ahead professionally but never able to fulfill company demands or their personal goals within the set financial framework and deadlines. It was also frustrating to lose time due to insufficient systems, colleagues' unavailability, and the pointless search for already existing knowledge. Lack of support and someone to complain to were also mentioned as disadvantages. The unpredictability of tasks and customers, which was proclaimed to be a great incentive, also caused a lot of stress, since it affected personal performance and salary. Finally, it was frustrating if one's professional pride was offended. This happened in cases where it was evident that the final outcome and one's performance could have been better had it not been for the time schedule and budget.

The results reveal that two concurrent aspects of knowledge work constitute a paradox: the same work-related or organizational issues could be experienced as both an opportunity and a source of stress.

\subsection{Stress management interventions in knowledge work}

The interviewees were also asked about how problems and work-related stress were managed, in order to identify the current management of problem issues within the knowledge-intensive companies, including the type of prevention practice (see Table 4). 
The typical reply was: "Why handle - there are no problems. Stress is a condition, and it is your own responsibility to draw the line if necessary". When the formally mandatory safety organization $^{2}$ was mentioned, this typically triggered a laugh and the following answer: "To use the safety organization is out of the question; it is only used in the industry."

It was thus clear that in practice, employees were primarily left to cope individually; it was their personal responsibility to draw the line, and this left them with a sense of loneliness. The majority of the interviewees expressed that they had learned to cope with the dilemmas in their job and to balance the pros and cons. As a consequence, each person is looking for individual strategies to manage the problems, for example by taking a day off or holiday or short sick-leaves, working faster and longer, and talking with colleagues and friends.

In severe cases, the employee would contact the project or department manager, but on a purely informal basis, which was also encouraged by the managers. The study also showed that any subsequent stress interventions typically focused on the individual in terms of individual stress management and strategies. Some of the examples mentioned were coaching, mentoring, time management, cognitive coping strategies, physical exercise programs etc. Therefore, most concrete activities were aimed at the individual and behavioral modifications, in order to improve the employee's ability to get back to work and be able to manage, resist and reduce the personal workrelated stress and problems.

The net result is that each individual is left with full responsibility for his/her own job performance and working life, and that the initiated interventions have an individual focus.

\subsection{In-depth analysis: Organizational causes of work-related problems}

\footnotetext{
${ }^{2}$ In Denmark, it is mandatory to establish a safety organization when a company has more than five employees. The objective of the safety organization is to ensure sound management of working environment issues within the company.
} 
As stated above, the working conditions associated with knowledge work are highly valued and appreciated but also constitute a series of problems. Evidently, the usual models used to analyze psychosocial working conditions do not provide a complete or adequate picture of the working conditions and human factors involved in knowledge work. While acknowledging the personal influence on the problems mentioned, this study aims to be proactive and the focus is thus on the organizational factors and how preventive activities can be initiated by aiming at the organizational structure and processes.

In order to understand the basic organizational causes behind the risk of work-related stress expressed by the respondents, the "Star Model" by Jay Galbraith has been used (Galbraith, 2002). It is a systemic model, in contrast to the "Six Golden Grains" presented earlier, which encompasses a set of non-related organizational factors that are given equal status.

The five components of the "Star Model" are included in the list of categories used to analyze the data in this study (see Table 4). By using the "Star Model", it is possible to address the mutual interdependencies and the relation to the basic elements in the organizational design. The organizational design model consists of five interrelated elements that form the foundation for organizational behavior, productivity and performance (see Figure 1). The model points out that by changing the organizational design, it is possible to change the behavior of the employees and managers and the company's performance. In this effort, a central factor is to acknowledge the interrelation of the organizational elements and make an attempt to align all five of them, in order to obtain the desired effect.

[Insert Figure 1] 
Application of the model makes it clear that all of the organizational conditions have an influence on knowledge-intensive work and thus on the working conditions. Use of the "Star Model" enabled the identification of a misaligned organizational design, which had an unsolicited effect on both the daily activities and the human factors, with the feeling of loneliness as one example.

\subsection{1 “WORKING WITH KNOWLEDGE CAN BE A LONELY JOB”}

In knowledge work, cooperation and networking play an essential role in order to obtain new projects and new knowledge and to coordinate knowledge. The interviewed employees describe themselves as open, helpful and social, and they express willingness to share knowledge and help when needed. However, if people do not cooperate or network, it also constitutes a serious problem, which has a negative impact on daily work. Consequently, the daily management has sharp focus on employees' social and communication competences, since they are necessary in order to secure cooperation and networking. A typical overall strategy in order to stay competitive is therefore to recruit the best candidates who possess both these abilities and the relevant knowledge.

Despite this focus and the open and helpful atmosphere, some of the respondents expressed their feeling of loneliness at work. They are for example left on their own to seek and share the necessary and adequate knowledge they need in order to perform through their personal network and databases, and find that it is their personal responsibility to succeed.

However, since a central activity like sharing knowledge is not rewarded in practice, either financially or culturally in terms of prestige or promotion, it is not carried out at a satisfactory level. The respondents stress the importance of this: the lack of access to relevant and new knowledge causes frustration, stress, repetition of mistakes, and loss of time due to impeded retrieval of information among colleagues. 
The individualized responsibility for knowledge production results in deficient management due to lack of coordination and an internally opaque project market, where employees only erratically trade their competences and time with their colleagues.

Internal tasks and processes, such as sharing knowledge and development of new concepts and knowledge, are not rewarded and cannot be invoiced. This affects the quality of the performance and products, which again affects both the professional pride of the employees and the company's prospective competitiveness. Furthermore, the individualized demands versus the decentralized structures constitute a dilemma. The result is that the self-managed employee (knowledge worker) does not have the expected influence.

By using the "Star Model" as a model of analysis, focus is on the organization of knowledge work, and it shows that loneliness is related to the basic elements in the organizational design (see Figure 2).

[Insert Figure 2]

The elements in the model are however not aligned, which is evident as the organizational design has an unsolicited effect on both daily activities and human factors. Accordingly, it is clear that a mutual dependency exists among the various conditions expressed in the "Star Model" and the employees' problems and strains.

\section{DISCUSSION}

The purpose of this section is to discuss the results just presented. The discussion is organized into subsections corresponding to the results in section 5 and the research question. In the last part of the discussion, the overall objective of the study is addressed. 


\subsection{New understanding of human factors and knowledge work}

Optimizing knowledge production and the premises for accomplishing this have been the primary focus in the knowledge management literature, which leaves out the human factor perspective (Heisig, 2009; Newell, Scarbrough, \& Swan, 2001). From a human factor point of view, this is understandable, since knowledge work has traditionally been characterized and understood to be a privileged and active job (Karasek, 1990). It has thus been possible to maintain that knowledge work comprises all the central aspects that support a sound and healthy psychosocial environment (Kristensen, 1999). This conclusion is in alignment with earlier studies of knowledge work that conclude that active jobs have a healthy psychosocial environment (Karasek, 1979; Karasek, 1990; Kristensen, 1999).

The classical models (Arnold, Cooper, \& Robertson, 1998; Karasek, 1979; Karasek, 1990) typically describe the organizational stressors as equal and non-related. However, because the interdependence between these features is not explicit, Galbraith's organizational design model has been used in this study. This model identifies the linkages between five different organizational conditions, and also focuses on the importance of fundamental organizational issues and work processes as the underlying variables. This is in contrast to the classical models, which focus on working conditions and their consequences.

The study reveals that two concurrent aspects of knowledge work constitute a paradox: the same work-related or organizational issue can be experienced as both an opportunity and a source of stress. The working conditions that are highly valued and appreciated thus also constitute a series of problems that are found to be demanding and have a severe influence on daily activities, performance and personal experiences. The stated problems correspond to previous studies of the increasing problems in knowledge work (Ipsen, 2007; McClenahan et al., 2007; Stavroula et al., 
2003; WHO, 1999), whereas the fact that knowledge work comprises a paradox between enthusiasm and stress is a new finding.

Evidently, the classic models do not provide the full picture of the sources of stress or of the workplace being at risk; they do not show that the same working condition can create both enthusiasm and stress and that knowledge work also constitutes risky working conditions. Therefore, close attention should be paid to what causes these experiences and how this 'paradox' is being managed and by whom, in order to revise the perception of knowledge work as a good and sound job per se and acknowledge that it puts a lot of stress on employees.

This study has thus contributed toward bridging knowledge work and the human factors literature to support a new understanding of both themes. This implies that future studies on workrelated stress, strain etc. need to embrace knowledge work and the production factors related to them. This study thus responds to the need for new knowledge that has been expressed in recent studies, which point at work-related stress as a critical and uncovered problem in knowledge work, affecting job performance, job satisfaction, labor turnover, absenteeism etc. (Allvin et al., 1998; Cox, Griffiths, \& Rial-González, 2000; Ipsen, 2007; Mogensen, Andersen, \& Ipsen, 2008).

\subsection{Individualized stress management practice}

As previously described, the employees were primarily left to cope individually, and it was their personal responsibility to draw the line. This left employees with a sense of loneliness. As a consequence, each person must find individual strategies to manage the problems.

The findings imply that, in practice, employees themselves managed the issues of current interest, such as job design, organization, distribution of assignments, stress etc., in an unstructured, incidental and informal manner. These descriptions of personal stress management can be seen as an attempt of primary coping (Cox, 1993), where one constructively tries to solve one's own 
problems. Our conclusion is that the managers and employees seem to have a mutual expectation that the individual takes responsibility for his own work and working life. A common mental model has been established about how problems are addressed and who has the responsibility to address and manage them. It is thus possible to talk about a transfer of responsibility for the working life at the workplace as well as the stress management, from the managers to the employees.

The study also shows that any subsequent stress interventions, termed secondary or tertiary interventions, focused typically on the individual in terms of individual stress management and strategies (M. Kompier \& Cooper, 1999; Murphy, 1988; Murphy \& Sauter, 2003). Examples of this are taking a day off or a holiday or short sick-leaves, working faster and longer, and talking with colleagues and friends. However, individual strategies such as these are short-sighted; they do not have a long-term preventive character, and do not address the organizational issues (Murphy, 1988).

The net result of this short-term and individualized prevention practice is a significant dysfunctional impact on both performance and working life. Consequently, no primary preventive interventions aimed at stressors related to the workplace are initiated.

Finally, the study shows that the mandatory committees and procedures were not capable of dealing with issues regarding working life, nor were they expected to. Evidently, problem management was kept within the line organization.

Based on the empirical findings, it has been shown that the working life of the knowledge workers is characterized by work-related issues that can be experienced as both an opportunity and a source of stress and thus constitute a paradox; and secondly, that the stress management interventions, in terms of both target and initiator, imply a transfer of responsibility from the managers to the individual employees.

\subsection{Individualized knowledge work}


Ipsen (2007), Sørensen and Holman (2010) and others have stated the importance of addressing the relation between the sources of work-related problems and the organizational design of the workplace.

Primary preventive changes are therefore to be made in the organizational design and not simply in relation to individual behavior modification. The analysis demonstrated that using classic models to study knowledge-intensive work provides a description of the conditions in the companies, but does not reveal the underlying determining variables in terms of organizational factors and how future primary preventive changes are to be addressed. However, when drawing on the "Star Model" by Galbraith (2002) to provide the analytical framework for the in-depth analysis, it is evident that it can be used to form the framework for greater systematization of the primary causes of work-related stress with regard to the presented psychosocial factors that have essential influence on working life. It also supports the claim that the organizational causes of the workrelated problems are related to the basic elements in the organizational design, which appear to be unaligned.

The study shows that the organizational design forms the basis for autonomy and influence on one's own work, which is expected and highly appreciated by the employees. Meanwhile, greater and greater demands are put on the employees to share knowledge, since this forms the key competitive parameter (T. H. Davenport \& Prusak, 1998; Drucker, 1988; Krogh \& Roos, 1996), and to comply with the budgets, thus emphasizing the importance of personal achievements and personal goals in relation to external tasks. The individualized responsibility for performance, in combination with the individual corporate reward systems, reinforce the individualized practice and can impede knowledge sharing, which is an essential part of knowledge work (Alvesson, 1995; Nonaka, Toyama, \& Konno, 2002; Starbuck, 1992). The organizational structure and the reward structure together make employees focus on where they can be acknowledged, motivated and 
praised, and make them compete among themselves on the basis of their knowledge and skills (Bason, Csonka, \& Ejler, 2003). Furthermore, it is the employees' own responsibility to seek the knowledge they need in their daily work and projects, which again can support the feeling of loneliness, since knowledge sharing is not rewarded in practice. The consequence of the individualized work is that the employees are left with the feeling of being in charge and free but also of being alone. From a corporate point of view, the result of this practice is that new initiatives are sidelined, because in contrast to the daily operations and earnings, they are not rewarded.

It is therefore possible to talk about an individualized practice where the individualized organizational structures, reward systems, corporate strategy etc. translates into a strong focus on operations and deliverables, and less focus on developing the business, where knowledge sharing is a key activity. This results in individualized knowledge work and a stress management practice where employees become self-managed, in charge of the daily production of knowledge and longterm development as well as the working life.

From a company point of view, the work processes are influenced negatively, and as a result, development of new concepts, standardization of processes etc. diminish, and productivity decreases. The overall organizational design thus has an unintended effect on the work processes and working life.

In relation to exploring the organizational options for preventing work-related problems in knowledge work, the applied models do not provide any instructions about how to solve these problems, but they do open for dialogue about how knowledge work is organized and the influence the design has on daily practices, the organization, and thus the working life of the knowledge worker. Evidently, the fundamental organizational issues and work processes, as the underlying variables, have to be considered and integrated in future preventive organizational changes. 


\subsection{Organizational options to primary preventive changes}

Based on the findings presented, options for primary preventive changes directed toward both managers and employees in knowledge-intensive companies are outlined in this section. The solutions to the listed problems are thus to focus on the work and the organizational design, the process in which the solutions are managed, and finally who this process involves.

\subsubsection{ORGANIZATIONAL COMPONENTS ARE INTERRELATED AND SHOULD BE ALIGNED}

By focusing on the work and the change of the organizational design, it is possible to change the behavior of the employees and managers and the company's performance. In this effort, a central factor is to acknowledge the interrelation of the organizational elements and make an attempt to align all five of them, in order to obtain the desired effect. This approach should be viewed as a supplement to the existing preventive initiatives, which focus on the individual.

The prerequisite for primary preventive changes is the alignment of the organizational components in order to support the desired performance and behavior. In the light of Galbraith's "Star Model", the analysis suggests that the organizational conditions should be discussed and changed. Examples of such conditions could be the individualized incentive structures, the work processes, the organizational structure, the recruitment practices, the role of the billing practice, conflicting job demands and knowledge sharing.

\subsubsection{MAKE TACIT KNOWLEDGE EXPLICIT REGARDING PROBLEMS, CAUSES AND SOLUTIONS}

If primary alignments are to be established, a joint optimization of production and working conditions has to be established. This opens for identification of potential primary intervention strategies and the design of new stress management practices using the achieved knowledge. 
We therefore also propose a collective dialogue within the companies about how the work is organized and the influence knowledge work has on the design of daily practices and the organization, and thus the working life of the knowledge worker.

The study shows that both employees and managers possess tacit and individual knowledge about the problems associated with knowledge work, and also about the causes and potential solutions. Due to this, no primary preventive changes are initiated. If this knowledge could be shared and made explicit, it would be possible to develop and design new ways of organizing and managing knowledge work so that the human factor perspective could be integrated in the organizational design. We therefore suggest that collective rooms for reflection be developed as an organizational framework in which both managers and employees can participate and talk about the factors that affect quality and efficiency in the work. The collectivities should also support the development of solutions to real problems. Examples could be new ways of organizing meetings and feedback processes. Changes in the daily work and its organization and management could in this way constitute a preventive effort to support the psychosocial work environment and employees' working lives.

\subsubsection{A COLLECTIVE STRESS MANAGEMENT PRACTICE SHOULD BE ESTABLISHED}

To secure the primary preventive changes, the solutions and thus the preventive changes should be integrated in the daily management practice, so that it is not up to each individual to cope with and find solutions to problems which are basically related to the organization and management of the work. A similar argument for integrating ergonomic interventions in the organizational strategy as a means to develop the total efficiency has been made by Porter (Porter, 1998). This organizational change would support a systematic and collective stress management practice instead of it being random and individualized. 
It is however important to note that the establishment of collective stress management practice can be complicated due to the individualized reward systems and performance measurements, thus making it difficult to act. Despite this reservation, it is essential to support the development of collectivities to secure commitment and motivate employees, in order to secure continuous improvement and operations.

\subsubsection{CENTRAL ACTORS SHOULD BE IDENTIFIED}

Following such an initiative, it is important to identify who will be involved in the development and management of the preventive changes. The study shows that the persons who are closely related to the daily production and performance are the major actors when the organizational design is to be changed. This means first line managers, project managers and employees (knowledge workers). They embrace the core knowledge of the daily processes and problems as well as the possible solutions. The role of human factor specialists and shop stewards is unclear, as they primarily/typically focus on physical working conditions. The human resource department is a more obvious actor/partner, as it is already involved in employee assistance programs and in sparring with the managers; however, its role in primary preventive changes is unclear and should thus be studied/identified.

To accompany the advancement of organizational options to prevent work-related stress in knowledge work, all central actors in knowledge-intensive work/companies must understand the impact that organizational design has on performance and working conditions, as well as the stress management practice and their role in this practice.

\subsection{Limitations of the study}


Due to the small size of the population, the representivity might be questioned; therefore, the scope of this study is to formulate a hypothesis for future studies within prevention of work-related stress in knowledge work, and to open a dialogue with managers in knowledge-intensive companies on preventive actions in accordance with general principles of hermeneutics. Further empirical evaluations are therefore needed to replicate the findings in different contexts and surroundings, with a different research methodology

The first limitation concerns the human factor phenomenon that was studied within the context of knowledge work with different results than previously documented. This study deals with an important issue by trying to bridge knowledge work and human factor research through focus on the organizational factors using a systemic model. This is in contrast to traditional models, which encompass a set of non-related organizational factors that are given equal status with focus on working conditions and their consequences. In future studies, it would be interesting to use the systemic approach in order to support the claim put forward in this paper.

The second limitation has to do with the extent to which these studies can be generalized. This project is based on empirical studies of knowledge work in three consulting companies and two consulting engineering firms, which represent companies characterized by work processes with non-material input and output, with individuals as the primary bearers of knowledge ("pure" knowledge companies (Alvesson, 1995)). It would thus be relevant to focus on other types of knowledge work and knowledge-intensive firms where knowledge is materialized and embedded in a technology (high-tech companies), such as biotech and IT companies, in order to explore and identify whether work-related stress is solely a problem in workplaces working with immaterial knowledge. Together, the studies would provide a full and qualified picture of knowledge work and work-related stress. 
Thirdly, the aim of the research questions has been organizational preventive changes based on collective action. This approach could mean that successful individual preventive actions are not identified and credited.

The last limitation has to do with the national aspect, as the study is entirely based on Danish workplaces. With reference to the study of Hofstede (Hofstede, 1980), Denmark is characterized as having a low power distance and a focus on process and not only results. It might therefore be interesting to look into studies with the same research question conducted within other national or regional cultures in order to identify cultural determinants behind the findings.

It is therefore recommended that future studies of human factors in knowledge work, stress management intervention as well organizational preventive changes therefore have an international approach.

\section{CONCLUSION}

The exploration of the nature and foundation of human factors and knowledge work is still at the developmental stage, which leaves a lot of room for further research, particularly of an interdisciplinary nature. While the field of knowledge management has typically been eager to develop new models and approaches, it has paid less attention to the human factors and the dependent variables. This paper has explicated a set of organizational factors that need to be addressed when knowledge-intensive companies seek to prevent work-related problems. It has also investigated the implications for the central actors, thus bridging knowledge work and human factors.

One of the most important findings that emerged is that un-alignment of the organizational design can explain employees' experiences and the problematic conditions of the work. A closer look at the companies' organizational design shows that the structure mainly supports self- 
management and individualized work, whereas collective and supporting structures that could prevent problems are lacking. In combination with employees' high qualifications and competences due to the companies' strategic recruitment policy, the results are obvious; the organizational design is aligned in such a way that it supports individual behavior and performance. The organizational parameters are not inherently inappropriate, but the combination of individualized structures, reward systems, strategy, and highly educated and autonomous employees all contribute to a practice with a dominating focus on operations and deliveries, and less focus on activities such as knowledge creation and sharing. Performance thus varies and fluctuates, resulting in reduced efficiency, inferior solutions, and employees who experience stress and frustration and offended professional pride etc. as part of their job.

Despite the organizational root of the problems, the typical stress management practice was shown to be individualized. Each person is looking for individual strategies to manage the problems. The net result of this short-term and individualized prevention practice is that each individual is left with full responsibility for his/her own job performance and working life, with a significant dysfunctional impact on both of them. Consequently, no primary preventive interventions are initiated that aim at stressors related to the workplace.

With regard to the aim to explore the organizational options for preventing work-related stress in knowledge work, it can be concluded that preventive changes are constituted by an alignment of the central components in the organizational design, seen from a human factor perspective. An understanding of the interrelation of the components is required in order to design a new organization that supports the desired performance and behavior. This also requires an explication of employees' and managers' tacit knowledge; therefore, it is suggested that collective rooms for reflection are established, where problems and solutions can be addressed. The collective approach 
should also address the stress management practice, so employees are not left to cope and draw the line individually, leaving them with a sense of loneliness

Finally, the central actors to be involved in the development and management of the preventive changes need to be identified. As the study shows, the persons who are closely related to the daily production and performance are the major actors, when the organizational design is to be changed.

New knowledge is needed, however, about how these preventive changes can be implemented. In future research, it would therefore be appropriate to examine a number of factors. For example: What initiates the desire for prevention of work-related stress? Which actors can facilitate this process? What specific recommendations can be developed and identified? Which organizational changes result in reduction of stress while also improving work processes? It would also be interesting to study whether it is possible to implement an organizational change when the different organizational factors are aligned. 


\section{REFERENCES}

\section{References}

Allvin, M., Aronsson, G., Hagström, T., Johansson, G., Lundberg, U., \& Skärstrand, E. (1998). Gränslöst arbete eller arbetets nya gränser. delstudie I. No. 2:I).Arbetslivsinstitutet.

Alvesson, M. (1995). Management of knowledge-intensive companies. Berlin: Walter de Gruyter.

Alvesson, M. (2004). Knowledge work and knowledge-intensive firms. New York: Oxford University Press.

Arnold, J., Cooper, C. L., \& Robertson, I. T. (1998). Work psychology - understanding human behaviour in the workplace. UK: FT Prentice Hall.

Bason, C., Csonka, A., \& Ejler, N. (2003). Arbejdets nye ansigter. ledelse af fremtidens medarbejder. Kфbenhavn: Bфrsens Forlag A/S.

Bryman, A. (2004). Social research methods (2nd ed.) Oxford University Press.

Buch, A., \& Andersen, V. (2008). Knowledge work and stress - beyond the job-strain model.

Collis, J., \& Hussey, R. (2003). Business research. New York: Palgrave Macmillan.

Cox, T. (1993). Stress research and stress management: Putting theory to work. No. 61).Health and Safety Executive.

Cox, T., Griffiths, A., \& Rial-González, E. (2000). Research on work-related stress. Nottingham, UK: European Agency for Safety and Health at Work.

Dahler-Larsen, P. (2002). At fremstille kvalitative data. Odense: Odense Universitetsforlag. 
Davenport, T. H., \& Prusak, L. (1998). Working knowledge. how organizations manage what they know. Boston, Massachusetts: Harvard Business School Press.

Davenport, T. H. (2005). Thinking for a living: How to get better performance and results from knowledge workers. Boston, Mass.: Harvard Business School Press.

DeFrank, R. S., \& Cooper, C. (1987). Worksite stress management interventions: Their effectiveness and conceptualization. Journal of Managerial Psychology, 2, 4-10.

Dettinger, K. M., \& Smith, M. J. (2006). Human factors in organizational design and management. In Salvendy, \& Gavriel (Eds.), Handbook of human factors and ergonomics (3rd ed., pp. 513) John Wiley and Sons.

Drucker, P. F. (1988). The coming of the new organization. Harvard Business Review, (-), 45-53.

European Foundation for the Improvement of Living and Working Conditions. (2007). Workrelated stress.

Galbraith, J. R. (2002). Designing organizations. an executive guide to strategy, structure and process. San Francisco, California: Jossey-Bass.

Griffiths, A. (1999). Organizational interventions. facing the limits of the natural science paradigm. Scandinavian Journal of Work Environment Health, 25(6), 589-596.

Heisig, P. (2009). Harmonisation of knowledge management - comparing 160 KM frameworks around the globe Emerald Group Publishing Limited.

Hofstede, G. (1980). Culture's consequences : International differences in work-related values. Beverly Hills ; London: Sage. 
Ipsen, C. (2006). Knowledge work and work-related stress.

Ipsen, C. (2007). Vidensarbejderens sarlige arbejdssituation og muligheder for forebyggelse af arbejdsrelateret stress $i$ vidensarbejdet - et kvalitativt studie af arbejdsrelateret stress $i$ vidensarbejdet. Department of Management Engineering, DTU).

Johnson, R. B., \& Onwuegbuzie, A. J. (2004). Mixed methods research: A research paradigm whose time has come. Educational Researcher, 33(7), 14; 3700093-26.

Johnson, R. B., Onwuegbuzie, A. J., \& Turner, L. A. (2007). Toward a definition of mixed methods research. Journal of Mixed Methods Research, 1(2), 112-133.

Karasek, R. (1979). Job demands, job decision latitude, and mental strain: Implications for job redesign. Adminstrative Science Quarterly, 24, 285-308.

Karasek, R. (1990). Lower health risk with increase job control among white collar workers. Journal of Organizational Behaviour, 11, 171-185.

Kompier, M., \& Cooper, C. (1999). In Cooper C., Kompier M. (Eds.), Preventing stress, improving productivity. european case studies in the workplace. London: Routledge.

Kompier, M., Geurts, S. A. E., Gründemann, R. W. M., Vink, P., \& Smulders, P. G. W. (1998). Cases in stress prevention: The success of a participative and stepwise approach. Stress Medicine, 14, 155-168.

Kristensen, T. S. (1999). Challenges for research and prevention in relation to work and cardiovascular diseases. Scandinavian Journal of Work Environment Health, 25, 550-557.

Kristensen, T. S. (2004). De 6 guldkorn. Retrieved 
Kristensen, T. S., Hannerz, H., Hфegh, A., \& Borg, V. (2005). The copenhagen psychosocial questionaire - a tool for assessment and improvement of the psychosocial work environment. Scandinavian Journal of Work, Environment \& Health, (31), 438-449.

Krogh, G., \& Roos, J. (1996). Managing knowledge. perspectives on cooperation and competition. London: Sage Publications.

Kvale, S. (1994). Interview. en introduktion til det kvalitative forskningsinterview. Kфbenhavn: Hans Reitzels Forlag.

Maalce, E. (2002). Casestudier. af og om mennesker i organisationer Akademisk.

McClenahan, C. A., Giles, M. L., \& Mallet, J. (2007). The importance of context specificity in work stress research: A test of the demand-control-support model in academics. 2007, 21(1), 85-95.

Mikkelsen, B. (1995). Participation - concepts and methods. In Methods for development work and research (pp. 61-84) Sage Publication Inc.

Mogensen, M., Andersen, V., \& Ipsen, C. (2008). Ambiguity, identity construction and stress amongst knowledge workers: Developing collective coping strategies through negotiations of meaning.

Murphy, L. R. (1988). Workplace interventions for stress reduction and prevention. In C. Cooper, \& R. Payne (Eds.), Causes, coping \& consequences of stress at work (pp. 301-339) John Wiley \& Sons Ltd.

Murphy, L. R., \& Sauter, S. L. (2003). The USA perspective: Current issues and trends in the management of work stress. Australian Psychologist, 38(2), 151-157. 
Newell, S., Scarbrough, H., \& Swan, J. (2001). From global knowledge management to internal electronic fences: Contradictory outcomes of intranet development. British Journal of Management, 12(2), 97-111.

Newton, T., Handy, J., \& Fineman, S. (1995). "Managing"stress. emotion and power at work (1st ed.). London: Sage Publications.

Nonaka, I., \& Takeuchi, H. (1995). The knowledge-creating company. New York: Oxford University Press.

Nonaka, I., \& Teece, D. (2002). Managing industrial knowledge - creation, transfer and utilization

Nonaka, I., Toyama, R., \& Konno, N. (2002). SECI, ba, and leadership. In I. Nonaka, \& D. Teece (Eds.), Managing industrial knowledge - creation, transfer and utilization (pp. 13-43)

Parker, S. K., \& Wall, T. D. (1999). Job and work design (1st ed.). London: Sage.

Porter, M. (1998). Justyfying the incorporation of ergonomics into organisation strategy - beyond single issue solving. Advances in Occupational Ergonomics and Safety : Proceedings of the XIIIth Annual International Occupational Ergonomics and Safety Conference 1998 Annual International Occupational Ergonomics and Safety Conference, 1998. 119.

Smith, M. J. \& Sainfort, P. C. (1989). A balance theory of job design for stress reduction. International Journal of Industrial Ergonomics, 4, 67-79.

Sørensen, O. H., \& Holman, D. (2010). Job-reredesign in knowledge work. In P. Vink, \& J. Kantola (Eds.), Advances in occupation, social, and organizational ergonomics (1st ed., pp. 111) CRC Press, Taylor \& Francis Group. 
Starbuck, W. H. (1992). Learning by knowledge-intensive firms. Journal of Management Studies, 6(29), 713-740.

Statens Institut for Folkesundhed. (2003). Stress - et folkesundhedsproblem (uge 5 - 2003). Retrieved

Stavroula, L., Griffiths, A., \& Cox, T. (2003). Work organisation \& stress. Switzerland: WHO.

WHO. (1999). The burden of occupational illness WHO. 